\title{
Study of a measuring and attenuation device prototype for essential and Parkinsonian tremors
}

\author{
Molina TSS*, Castilho MS*, Tsurumaki AH* and Del Monaco ADM§ \\ *Pontifical Catholic University of São Paulo (PUC-SP), Brazil. §Federal University of ABC \\ (UFABC), Brazil.
}

\begin{abstract}
People who suffer from Essential Tremor or Parkinson's disease have trouble performing daily tasks such as eating, drinking and writing, leading to weight loss and even depression in some situations. It causes social embarrassment and functional incapacity, being responsible for about $25 \%$ of the changes of work or distance of the same. Treatment of tremors it is ineffective in about $25 \%$ of patients has side effects with the use of drugs and can cause hemorrhages and psychiatric manifestations in neural treatments. In order to bring new therapeutic options to control tremor, the present work aims to develop a non-invasive tremor attenuation device with the use of inertia flywheels. An experimental model was developed to simulate the tremors composed of servo motor and two inertial wheels and, with the use of inertial sensor and Arduino, analyzes of tremor behavior were done according to the inertia flywheel. The acquired data showed that the tremor was attenuated by about $28 \%$. Lastly, a printed glove was developed in $3 \mathrm{D}$ printer, in which two flywheels were coupled, being a feasible alternative in the non-invasive treatment of tremors.
\end{abstract}

Keywords. Tremor, Essential Tremor, Parkinson Tremor, Attenuation, Non-Invasive.

Introduction. One of the most common movement disorders found in clinical practice is tremor, defined as an involuntary, oscillatory and rhythmic movement, approximately sinusoidal in one or more parts of the body, produced by the synchronous or alternating contraction of antagonistic muscles $[1,2]$.

Currently, people who suffer from Essential Tremor (ET) or Parkinson's Disease (PD) have problems performing daily tasks, such as eating, drinking and writing, causing, in some situations, weight loss and even depression. In addition, the tremor often causes social embarrassment and functional disability, being responsible for about $25 \%$ of changes in work or removal from work $[3,4,5]$.

The treatment of tremors is based on drugs, surgery or deep brain stimulation, the latter two options being typically used in patients immune to drugs [2, 6]. However, $25 \%$ of patients do not improve with treatment, the drugs used induce side effects and neurosurgery is associated with hemorrhages and psychiatric manifestations [3, 7]. In addition, patients suffering from TE do not have an 
effective treatment option based on pharmacotherapy. As a result, many patients do not receive any treatment, even though $73 \%$ of TE patients have a reported disability. Such reasons make research on new therapeutic options to control tremor mandatory $[2,8,9,10,11,12]$.

Thus, the present work aims to develop a tremor attenuation device with the use of flywheels.

To this end, an experimental model was developed in order to simulate the tremors composed by a servo motor, two flywheels, MPU6050 inertial sensor and Arduino. From this model, it was possible to control the frequency of the tremor, which varies between $4 \mathrm{~Hz}$ and $22 \mathrm{~Hz}$. In addition, measurements were made without and with the flywheels, turned on and off. Subsequently, the data obtained were analyzed in order to identify the attenuation of the tremor in each of the situations.

Materials and methods. The first step of this project was a development of a device that is composed by servo motor, it was used to simulate the tremors, in order to control the motor rotation frequency, between $4 \mathrm{~Hz}$ and $22 \mathrm{~Hz}$, which cover the range of frequencies reached by the essential and parkinsonian tremors. First, the MEMS MPU6050 sensor was attached to the servo motor to perform the first data capture, in order to generate the frequencies within the desired scale. For this, the following parameters were established in the servo programming, through the Arduino IDE software:

- Speed of the servo varying in the values of 140, 160 and 175. These speeds were established taking into account the VarSpeedServo.h library, which establishes a variation from 0 to 255, with 255 being the fastest.

- Data acquisition time of approximately 25 seconds;

After the first analysis of the frequencies generated by the servo motor, a new experimental arrangement was developed, consisting of an aluminum support, screwed into the servo motor . The sensor was attached to this support. The tremor data was captured according to the parameters mentioned above, obtaining a frequency graph for each speed value programmed in the servo motor. The acquisition of the data considered only the genuine tremor, without adding the flywheels coupled to the motors as an actuator in reducing the amplitude of the tremors.

To capture the tremor data, the MPU6050 sensor was connected to the Arduino Nano, according to the specifications provided in the Arduino datasheet. Then, the Arduino Nano was connected to the computer via a USB cable.

Use the Arduino IDE software to develop a project schedule. In this case, a code was used that allows reading and capturing values acquired in the $\mathrm{X}, \mathrm{Y}$ and $\mathrm{Z}$ axes of the gyroscope and accelerometer present in the MPU6050.

The Serial Monitor is responsible for the communication between the computer and the board. Through it was possible to read the data acquired in the X, Y and Z axes of the MPU6050. 
The data, read in the Serial Monitor of the Arduino IDE, were entered in Excel 2015 in order to make a graphical analysis in the time domain of the results obtained in the $\mathrm{X}, \mathrm{Y}$ and $\mathrm{Z}$ axes. Then, the mean, median and standard deviation of the tremor data, thus obtaining the percentage of attenuation in each axis, according to the weight insertion in the motor support.

The data obtained in the Serial Monitor were also analyzed with the help of the Matlab program, through Fast Fourrier Transform, which performs the transfer of graphics in the time domain to the frequency domain.

A battery electric circuit was developed in the Multisim 13.0 Software, to supply the micromotors inserted in the attenuator assemblies, which consume $5.9 \mathrm{~V}$ at its maximum efficiency. This circuit consists of $43 \mathrm{~V}$ batteries. Such batteries are signaled by numbers 1 and 2 , which indicate the direction of connection of the batteries. Thus, two batteries were connected in series, totaling $6 \mathrm{~V}$. The other two were connected, also in series, but with direction 2, totaling - 6V.

Results and discussion. The tremor data was obtained every 10 milliseconds, that is, 100 data per second, according to the Nyquist criterion. All results were analyzed on the $\mathrm{X}, \mathrm{Y}$ and $\mathrm{Z}$ axes, in order to understand which axis shows the most fundamental peaks of frequency. FFT was applied to the data acquired in the time domain to transform this data into the frequency domain, generating the graphics with frequency response.

Thus, the data obtained from the accelerometer were adopted for the analysis of the data, due to the experimental arrangement assembled to simulate a lateralized tremor.

The measurements were made, which characterized the positive results, proving the effectiveness of the attenuator sets. These results can be seen in Graphs 1, 2, 3, 4 and 5, which show the series in the frequency spectrum after applying the FFT.

These graphs show three series, except the 1, which presents only two series (red and green), of results acquired during the measurement. The series in red shows the values of the genuine tremor, in which it is possible to observe the highest peak of fundamental frequency. The green series corresponds to the tremor attenuated by the attenuating assemblies at their maximum voltage (6V) and the blue series corresponds to the tremor attenuated only with the weight of the attenuating assemblies (223.26g).

Graph 1 shows the result of the first measurement after the steering wheels are corrected. It is possible to visualize a significant attenuation of the fundamental frequency peak, which is approximately $4 \mathrm{~Hz}$, with the insertion of the attenuator sets. However, this graph has a lot of noise and no comparative analysis with the weight of the sets was made. Therefore, the sampling frequency was increased in the Arduino programming, according to the Nyquist criterion, so that the analog signal could be reproduced without aliasing errors. Fig. 1: 


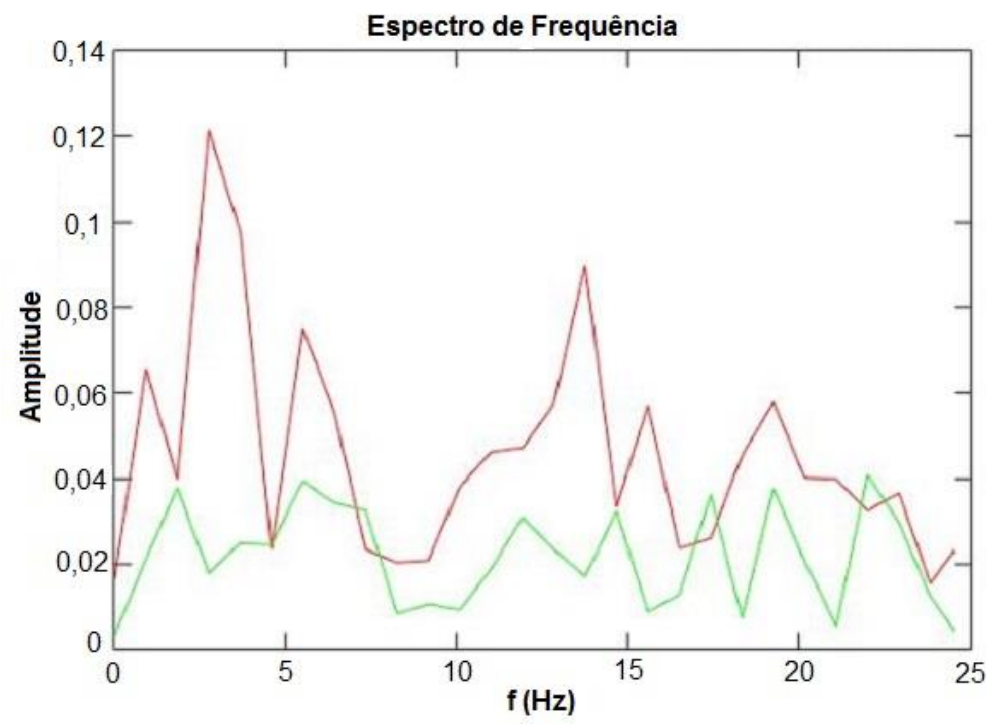

Figure 1. Frequency domain tremor with 160 servo motor speed. Red: without attenuation. Green: with attenuation dispositive on.

Graphs 2 and 4 were acquired in the frequency domain and show the fundamental frequency peak very evident at approximately $17 \mathrm{~Hz}$ and $22 \mathrm{~Hz}$, respectively. When increasing the sampling frequency of the analog signal, the fundamental frequency of the tremor also increased and the attenuator sets showed an efficiency similar to the measurement in Graph 6, which presents approximately $4 \mathrm{~Hz}$ of fundamental frequency.

In these graphs, it is possible to observe the attenuation of the peak of the red series, genuine tremor, with the inclusion of the attenuator sets on (green series) and off (blue series).

In order to facilitate the visualization of the aforementioned series, Graphs 2 and 4 were zoomed in, as can be seen in Graphs 3 and 5, respectively.

In Graph 3, it can be seen that the genuine tremor (red serious) has an amplitude of $18^{\circ} / \mathrm{s}$, while the tremor with the attenuator sets off (blue serious) has an amplitude of approximately $15.7^{\circ} / \mathrm{s}$, for example. Finally, the tremor with the attenuator sets connected (green series) has an amplitude of approximately $14.8^{\circ} / \mathrm{s}$. Thus, it can be said that the disconnected attenuator sets attenuated the tremor by $13 \%$, while the connected attenuator sets attenuated the tremor by $18 \%$. Fig 2 : 


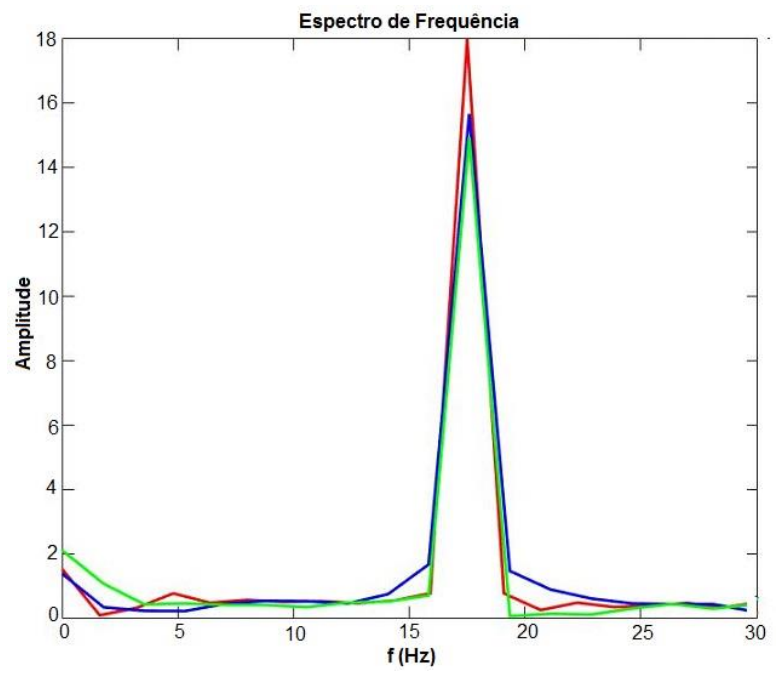

(2)

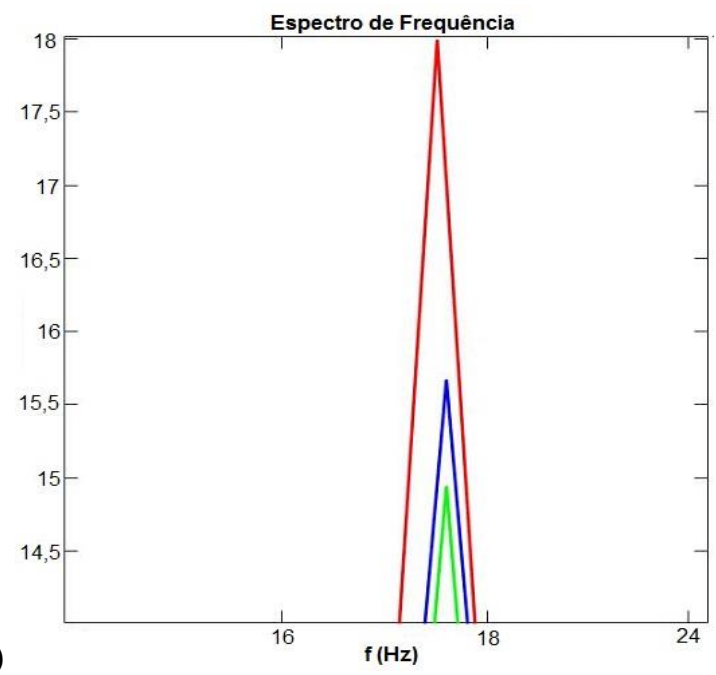

Figure 2. Graph 2: Quake in the frequency domain with speed on the 140 servo motor. Graph 3: Zoom to the fundamental peak of series in Graph 2.

In Graph 4, we observed a similar behavior shown in Graph 2. The genuine tremor (red series) has an amplitude of $15^{\circ} / \mathrm{s}$, while the tremor with the attenuator sets off (blue series) has an amplitude of approximately $13.5^{\circ} / \mathrm{s}$ and, finally, the tremor with the attenuator sets connected (green series) has an amplitude of approximately $10.8^{\circ} / \mathrm{s}$. Thus, it can be said that the disconnected attenuator sets attenuated the tremor by $10 \%$, while the connected attenuator sets attenuated the tremor by 28\%. Fig 3:
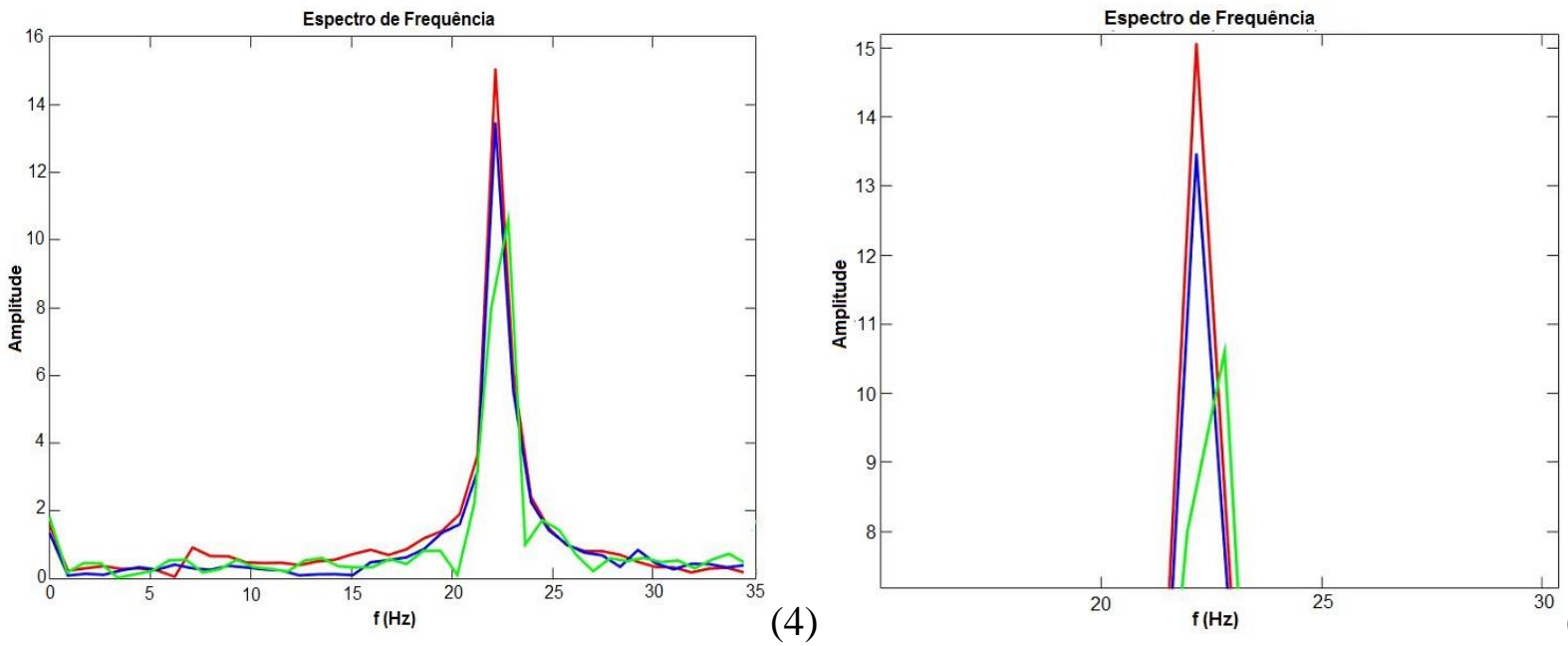

Figure 3. Graph 4: Measurement of tremor in the frequency domain with speed on the 175 servo motor. Graph 5: Zoom of fundamental peak series in Graph 4. 
The final construction of the developed prototype can be seen in Figure 4, which shows the glove with the two attenuator sets and a black box, in which is the battery circuit. Fig 4:

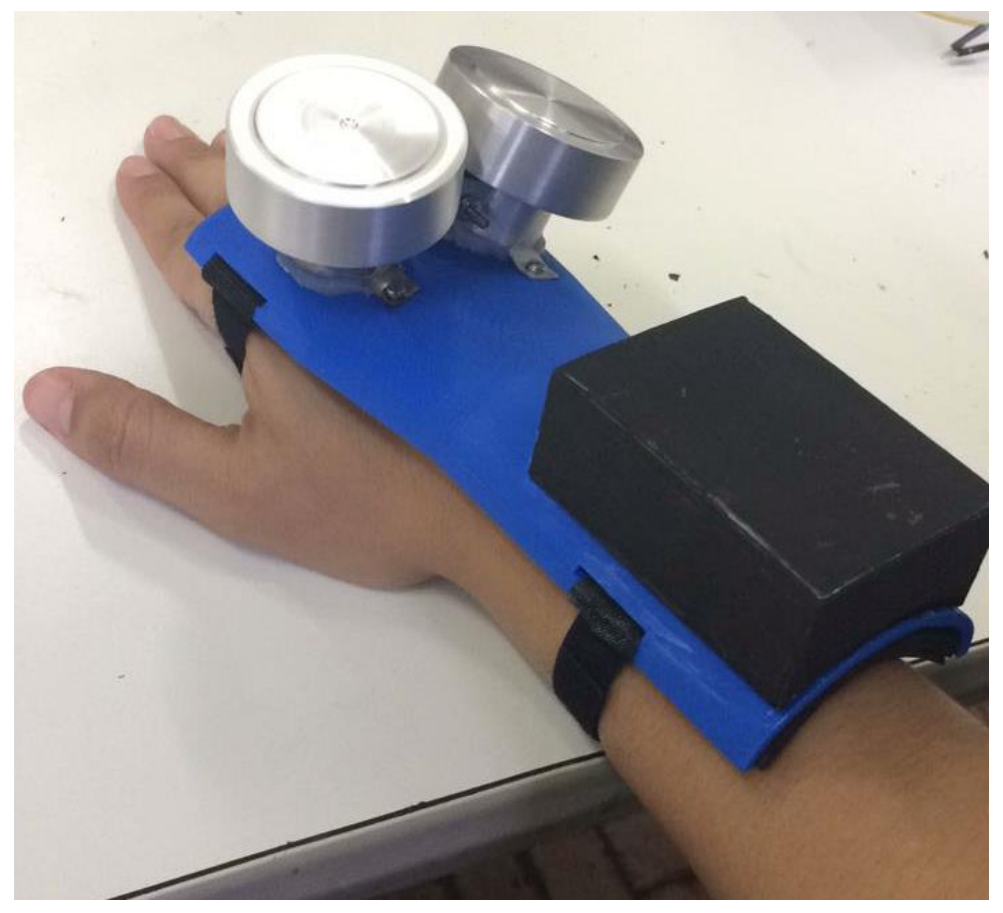

Figure 4. Device prototype

Conclusion. In view of the results obtained and analyzed, we can affirm that the use of attenuator sets, composed of flywheels, for the quake mitigation is an effective and more efficient solution than the quake mitigation with weights alone.

Being possible to analyze the tremor in a more consistent way, we observed that the maximum attenuation of the tremor with weights is approximately 13\%, while the maximum quake attenuation with flywheels is approximately $28 \%$.

Finally, a future improvement for the glove will be the implementation of a system using the MPU6050 sensor and the Arduino, capable of measuring the tremor and, according to the amplitude read, the attenuator assemblies will be connected with sufficient voltages for their mitigation. In addition, these data can be stored and used by doctors in order to monitor the patient's condition.

Disclosure. The authors report no conflicts of interest in this work. 


\section{References.}

(1) KURY, L.K.P., PEREIRA, A.A., ANDRADE, A.O. A utilização da eletromiografia na avaliação qualitativa e quantitativa dos tremores. 2007. Artigo publicado na V CEEL Universidade Federal de Uberlândia.

(2) TESKEY, W. J. E. Assessment and Attenuation of Movement Disorder Motion using Inertial Sensors. 2011. University of Calgary.

(3) GALlEGO, J.A., ROCON, E., ROA, J.O., MORENO, J.C., PONS, J.L., Real-Time Estimation of Pathological Tremor Parameters from Gyroscope Data. Sensors, Arganda del Rey. ISSN 14248220. 2001.

(4) Borges V, Ferraz HB. Tremores. Neurociências, v.14, n.1, 2006.

(5) HENDERSON, E. N. An inertial measurement system for hand and finger tracking. 2011. Boise state university graduate college.

(6) GRIMALDI, G., MANTO, M. Neurological Tremor: Sensors, Signal Processing and Emerging Applications. Sensors, Bruxelas. ISSN 1424-8220. 2010.

(7) PINTO, M.D.C.L. Tremor Essencial Visão global da doença. 2013. Dissertação (Mestrado em Medicina) - Universidade da Beira Interior, Covilhã.

(8) SAHAH, V., Singh, G., Goyal, S. A Control-System Perspective on Parkinsonian Tremor with Implications on Diagnosis and Disease Monitoring. 2014.

(9) BERGAMINI, M.G., DANVANSO, L.S. Medidor de tremor para diagnóstico de Mal de Parkinson. Conic Semesp. 2014.

(10) GOULART, F., PEREIRA, L.X. Uso de escalas para avaliação da doença de Parkinson em fisioterapia. Fisioterapia e Pesquisa. 2004. Belo Horizonte.

(11) SHAH, V.V., GOYAL, S., MADAPUSI, H.J.P. Linking Increased Response Time to Rest Tremors in Parkinson's Disease: A Feedback Control Perspective. 2015. Califórnia.

(12) DAI, H., ZHANG, P., LUETH, T.C. Quantitative Assessment of Parkinsonian Tremor Based on an Inertial Measurement Unit. Sensors. Jinjiang. ISSN 1424-8220. 2015. 